\title{
Epigenetic modifications of caveolae associated proteins in health and disease

\author{
Jin-Yih Low ${ }^{*}$ and Helen D. Nicholson
}

\begin{abstract}
Caveolae are small, "omega-shaped" invaginations at the plasma membrane of the cell which are involved in a variety of processes including cholesterol transport, potocytosis and cell signalling. Within caveolae there are caveolae-associated proteins, and changes in expression of these molecules have been described to play a role in the pathophysiology of various diseases including cancer and cardiovascular disease. Evidence is beginning to accumulate that epigenetic processes may regulate the expression of these caveolae related genes, and hence contribute to disease progression. Here, we summarize the current knowledge of the role of epigenetic modification in regulating the expression of these caveolae related genes and how this relates to changes in cellular physiology and in health and disease.
\end{abstract}

Keywords: Caveolae, Epigenetic, micro-RNA, Promoter methylation, Histone acetylation, PTRF, Caveolin-1, Caveolin-2, 5-AZA, Trichostatin-A

\section{Introduction}

Caveolae are small specialized "cave-like" microdomains at the plasma membrane that function as trafficking vesicles and are involved in organization of signal transduction. Caveolae are present in most tissues and are particularly abundant in cardiac, continuous endothelial and epithelial cells, as well as fat cells [1-3]. Within caveolae are caveolae associated proteins; caveolin-1 (CAV1) [4], caveolin-2 (CAV2) [5], caveolin-3 (CAV3) [6], Cavin-1 (also know as polymerase-1 and transcript release factor) (PTRF) [7], Cavin-2 [8], Cavin-3 [9] and Cavin-4 [10], which are important for the formation and maintenance of the caveolar structure.

CAV1 is a $22 \mathrm{kDa}$ protein which is the principal substrate of src kinase [11] and appears as a filament-like structure at the plasma membrane [12]. CAV1 is expressed in a wide range of tissues with the highest expression in smooth muscle cells, adipocytes, fibroblasts and endothelial cells [13]. CAV1 plays an important role in the formation of caveolae; if cells lack CAV1, no caveolae are observed [14] while, restoration of CAV1 expression results in the de novo formation of caveolae [15, 14]. CAV1 knock out mice demonstrate a variety of physiological defects

\footnotetext{
* Correspondence: lowji021@student.otago.ac.nz

Department of Anatomy, Otago School of Medical Sciences, University of Otago, P.O. Box 913, Dunedin 9054, New Zealand
}

including reduced renal calcium reabsorption and vascular and metabolic abnormalities [16-18]. CAV1 is also reported to be involved in diseases such as cancer, cardiovascular disease and diabetes (for review see [19]).

CAV2 is a $20 \mathrm{kDA}$ protein found abundantly in white adipose tissue [5]. Expression of CAV2 is independent of caveolae formation, however, co-expression of CAV2 with CAV1 results in more abundant invaginations and more uniform caveolae formation $[20,21]$. Thus while CAV2 may not be essential, it plays a supporting role in modulating the biogenesis of caveolae. CAV2 is expressed concurrently with CAV1 and can undergo hetro-oligomerization with CAV1 [22]. In addition, CAV2 has been shown to interact with CAV3 in cardiac muscle cells [23]. CAV2 knock out mice have normal distribution of caveolae but display a variety of lung disorders [21].

CAV3 has a molecular weight of $18-20 \mathrm{kDA}$ and is $85 \%$ similar to CAV1 [6]. It is predominantly expressed in muscle cells [6]. CAV3 co-immunoprecipitates with dystrophin, suggesting that dystrophin and CAV3 can exist as a discrete complex [24]. In embryonic fibroblasts derived from caveolae-null mice, restoration of $C A V 3$ successfully restores the formation of caveolae [25]. $C A V 3$ knock out mice show a loss of caveolae at the sarcolemma (but not endothelial cells), exclusion of dystrophin-glycoprotein complexes from the lipid rafts, 
abnormalities of the T-tubule system, insulin resistance and instability of the insulin receptor in skeletal muscle $[26,27]$. Similarly, analysis of cardiac muscle from $C A V 1$ knock out mice demonstrates a loss of caveolae in the cardiac endothelial cells but not cardiac myocytes, however the opposite observation was seen in $C A V 3$ knock out mice [28]. Only in CAV1 CAV3 double knock out mice were caveolae completely abolished in both cell types [28]. This suggests that $C A V 3$ can compensate for $C A V 1$ allowing caveolae formation in cardiac myocytes, providing some functional redundancy [28].

PTRF was cloned in 1998 and was first described to be involved in RNA transcription machinery $[29,30]$. PTRF is a resident protein in caveolae [31] and is widely expressed in a range of tissues, with highest expression in adipocytes, cardiac and skeletal muscles and osteoblasts [32]. The functional role of PTRF in caveolae formation has only recently been described. Loss of PTRF is accompanied by reduced numbers of caveolae [33, 34]. Re-expression of PTRF in cell lines that have reduced or lack PTRF results in caveolae formation [35, 7]. PTRF knock out mice lack caveolae and demonstrate glucose intolerance and disorders of the lungs and cardiovascular system [34, 36-39].

Structurally, Cavin-2 is $~ 20 \%$ similar to PTRF [40]. Although down-regulation of Cavin-2 in turn causes reduced PTRF and CAV1 expression (hence reduced caveolae number), suggesting the interdependency between these 3 molecules [8], the expression of Cavin-2 alone does not alter the number of caveolae $[40,41]$. However, the expression of Cavin-2 induces tube-like morphological changes to caveolae [40]. Cavin-3 is reported to be associated with CAV1 during caveolae budding [9]. The process of caveolae budding and trafficking of caveolae-associated vesicles along the microtubules is greatly impaired in the absence of Cavin-3, suggesting a role of Cavin-3 in intracellular transport mechanisms [9]. Cavin-4 is only present in muscle cells and is a cytosolic protein that is able to interact with Cavin-2. Cavin-4 has been demonstrated to be important in cardiac dysfunction where Cavin- 4 is able to modulate the Rho/ROCK pathway that is important for cardiac muscle biogenesis [42].

Changes in the expression of the caveolae related proteins are associated with disease. For example, expression of CAV1, CAV2 and PTRF is dysregulated in prostate and breast cancer [33, 43]. Furthermore, other health issues such as cardiovascular disease, inflammation and abnormal insulin signaling are associated with changes in these proteins $[44,39]$. However, what causes the change in expression of these caveolae related molecules is unknown. Potentially, these changes may be related to epigenetic or micro-RNA (miRNA) mechanisms that act upstream of the genes. This review brings together the current evidence for epigenetic regulation of these genes and thus, presence of caveolae. As there are limited data, or no evidence, published on CAV3, Cavin-2, Cavin-3 and Cavin-4, this review will focus on CAV1, CAV2 and PTRF.

\section{Review \\ Evidence for epigenetic changes related to CAV1, CAV2 and PTRF}

Epigenetics involves the study of the changes in gene expression that are independent of any changes in DNA sequences. There are two main mechanisms under the umbrella of epigenetics; DNA methylation, which involves the methylation of the promoter region of the gene and histone deacetylation which involves structural changes of the chromatin. Importantly epigenetic changes can be reversed with the use of chemical agents [45].

DNA promoter hypermethylation involves the modification of cytosine residues in the CpG dinucleotides to form 5-methylcytosine through covalent addition of a methyl group by the enzyme, DNA methyltransferase. In the mammalian genome, CpG dinucleotides are unevenly distributed to form short sequences that have high densities of $\mathrm{CpG}$ dinucleotides known as CpG islands (CpGi) [46], within the promoter region of the genome. Gene promoters which have their CpGi methylated are transcriptionally inactive as the methyl groups block the promoter region from being accessed by transcriptional elements [45]. Chemical agents such as 5-AZA-2'-deoxycytidine (5-AZA) have been reported to reverse DNA promoter hypermethylation [47-49].

More recent studies suggest that methylation can also occur in non-CpGi rich areas in the promoter region to silence gene expression. These regions have a lesser density of $\mathrm{CpGi}$ and are normally situated around $2 \mathrm{~kb}$ from the regular $\mathrm{CpGi}$ rich regions, and have been named CpGi shores [50, 51]. Hypermethylation at the CpGi shore appears to have a critical role in regulating gene expression [50]

Allfrey et al. [52] described that for gene expression to take place, the $\boldsymbol{\varepsilon}$-amino group in the lysine residue of the histone cores must be acetylated by histone acetyltransferases (HATs). Histone deacetylases (HDACs) cancel the effect of HATs by removing acetyl groups from the lysine residue in histone cores. The removal of acetyl groups by HDACs restores the positive charges on lysine residues. This causes the histone tails to coil tightly to the DNA leading to transcriptional inactivation as the transcriptional machinery is unable to access the DNA [52, 53]. The use of Trichostatin-A (TSA), a microbial metabolite capable of inhibiting HDACs, was first described in 1995 and has been used to re-express genes which are inactivated by histone deacetylation [54]. Gene transcription is restored when lysine residues in the histone tails are acetylated through inactivation of HDACs by TSA [54]. 
To date, most of the reports of epigenetic effects on CAV1 are related to DNA methylation and in the context of cancer (Table 1). It is suggested that the $5^{\prime}$ promoter of CAV1 is methylated in human breast cancer cell lines, MDA-MB-231, MCF7 and T-47D but not in normal human mammary epithelial cells [55, 43]. Studies of clinical tissues have shown that breast cancer tissues have hypermethylation of the CAV1 promoter accompanied by down-regulation of CAV1 expression when compared to adjacent normal breast tissues [56, 57]. Furthermore, CAV1 promoter hypermethylation is significantly associated with the histopathological grade of the tumor [56].

Nodal metastasis has been reported to be associated with CAV1 hypermethylation [58]. It has been suggested that inactivation of $C A V 1$ through hypermethylation drives the spread of breast cancer to the lymph nodes [58]. Treatment of breast cancer cell lines with 5-AZA successfully increases both CAV1 mRNA and protein $[43,59]$. However, in a subtype of breast cancer, inflammatory breast cancer (IBC), CAVI is reported to be hypomethylated resulting in overexpression of $C A V 1$ [60]. Therefore it may suggest that different breast cancer subtypes may have different changes in epigenetic regulation of CAV1.

Recent evidence suggests that $\mathrm{CpGi}$ shores are involved in regulation of $C A V 1$ expression. Treatment with a DNA methyltransferase inhibitor induces expression of CAV1 through demethylation of CpGi shores in breast cancer cell lines that have low $C A V 1$ expression (even though the CpGi rich promoters are hypermethylated) [61]. CpGi shores are reported to be hypermethylated in less aggressive breast cancer cells whereas hypomethylation of CpGi shores is observed in highly aggressive breast cancer cells [61].

In prostate cancer $C A V 1$ is down-regulated and this is accompanied by promoter hypermethylation of $\mathrm{CpGi}$ sites at the $5^{\prime}$ promoter region of CAV1 [62, 63]. Bisulfite sequencing suggests promoter hypermethylation may be a mechanism for down-regulation of $C A V 1$ gene expression [64]. However, loss of CAV1 expression was observed in androgen dependent LNCaP cells while increased expression occurred in PC3 cells and tissues from advanced cancer [33]. Thus, expression of CAV1 may be lost in the early stages of prostate cancer and promote cancer cell proliferation and survival, but upregulated at late stages of prostate cancer to favor metastasis, inhibit apoptosis and promote multi-drug resistance [65]. A possible explanation for the conditional role of $C A V 1$ as both tumor promoter and suppressor is the interaction of CAV1 with other effector molecules that may directly or indirectly interact with or affect CAV1's function [65]. Possible examples are Mgat5 and galectin-3. In early stages of prostate cancer, the expression of CAV1 is lost and the expression of Mgat5 and galectin-3 is at low levels. However, in later stages of prostate cancer, expression and formation of Mgat5/ galectin-3 lattices may stimulate and elevate the

Table 1 Involvement of CAV1 epigenetic modification in cancers

\begin{tabular}{|c|c|c|c|c|}
\hline Cancer types & Promoter hypermethylation & Histone modification & CAV1 expression & Changes in physiology and pathophysiology \\
\hline \multirow[t]{6}{*}{ Breast } & {$[55]$} & \multirow[t]{9}{*}{ [59] } & \multirow[t]{6}{*}{ Down-regulated } & \multirow{6}{*}{$\begin{array}{l}\text { Decreased migration after 5-AZA and TSA } \\
\text { treatment [59] }\end{array}$} \\
\hline & {$[57]$} & & & \\
\hline & [43] & & & \\
\hline & [56] & & & \\
\hline & [59] & & & \\
\hline & [58] & & & \\
\hline \multirow[t]{3}{*}{ Prostate } & [62] & & \multirow[t]{3}{*}{ Down-regulated } & \multirow[t]{3}{*}{ Not described } \\
\hline & [64] & & & \\
\hline & {$[63]$} & & & \\
\hline Bladder & {$[68]$} & & Down-regulated & Not described \\
\hline Ovarian & [71] & {$[71]$} & Down-regulated & $\begin{array}{l}\text { Over-expression of CAV1, reduced colony formation } \\
\text { and increased apoptosis in ovarian cancer cell line [71] }\end{array}$ \\
\hline Lung & {$[70]$} & & Down-regulated & $\begin{array}{l}\text { Over-expression of CAV1, reduced colony formation } \\
\text { in lung cancer cell line [70] }\end{array}$ \\
\hline \multirow[t]{3}{*}{ Colorectal } & [72] & & \multirow[t]{3}{*}{ Down-regulated } & \multirow[t]{3}{*}{ Not described } \\
\hline & [73] & & & \\
\hline & {$[74]$} & & & \\
\hline \multirow[t]{2}{*}{ Liver } & [75] & & \multirow[t]{2}{*}{ Down-regulated } & \multirow[t]{2}{*}{ Not described } \\
\hline & {$[77]$} & & & \\
\hline
\end{tabular}


expression of CAV1 through phosphorylation, resulting in up-regulated CAV1 expression in advanced prostate tumours [65-67].

Promoter methylation is also seen in a variety of other cancers and appears to be cell specific in a given organ (Table 1). For example, CAV1 promoter methylation is seen in undifferentiated small cell and squamous cell carcinoma but not in transitional cell [68] or primary adenocarcinomas and signet ring cell carcinomas of the bladder [69]. Similar cell specificity is seen in lung cancers [70].

Treatment with 5-AZA has been shown to restore $C A V 1$ expression in some cancers confirming hypermethylation. CAV1 expression is down-regulated in ovarian cancer cell lines but expression can be restored by treating the cells with 5-AZA [71]. CAV1 promoter hypermethylation has also been reported in sporadic colorectal cancer [72] and re-expression of CAV1 was observed in colon cancer cell lines after 5-AZA treatment [73, 74].

Promoter hypermethylation of CAV1 is also seen in hepatocellular carcinoma (HCC) cell lines [75] and $\mathrm{HCC}$ tissues and is accompanied by reduced expression of CAV1 [75]. Further, 5-AZA treatment causes upregulated $C A V 1$ expression in hepatoma cells [75]. One of the risk factors for hepatocellular carcinoma (HCC) is exposure to Hepatitis B Virus (HBV) and in particular to HBV's X protein. This protein is able to promote tumorigenesis through activation of signaling pathways, growth factors and oncogenes. Furthermore, HBV's X protein inactivates negative growth regulators such as p53 to favor metastasis [76, 77]. Interestingly, HCC samples that are infected with HBV show significant suppression of CAV1 expression through hypermethylation of $C A V 1$ 's promoter [77], due to the hypermethylation effect of HBV's $\mathrm{X}$ protein on CAV1's promoter (Fig. 1) [77].

Other than promoter hypermethylation, histone modification has also been reported as a mechanism to silence $C A V 1$ expression. In ovarian cancer cell lines, treatment with TSA up-regulates CAV1 [71] and in breast cancer cell lines, TSA treatment results in a 35 fold increase in CAV1 expression [59].

Estrogen receptors alpha $(E R \alpha)$ and beta $(E R \beta)$ are expressed in neuronal cells [78, 79]. Ectopic expression of ER $\alpha$ in SK-N-MC neuronal cells leads to epigenetic silencing of $C A V 1$ (and down-regulation of CAV1) while treatment with 5-AZA and TSA results in partial restoration of CAV1 expression. However, when ER $\beta$ is coexpressed with ER $\alpha$ in SK-N-MC cells, the effect on $C A V 1$ is abolished, suggesting ER $\beta$ counteracts the effect of $\mathrm{ER} \alpha$ on $C A V 1$ down-regulation through an epigenetic pathway (Fig. 2) [80]. However, the exact molecular mechanism is not well understood and this observation may be due to a direct ER $\alpha$ targeting effect or indirect
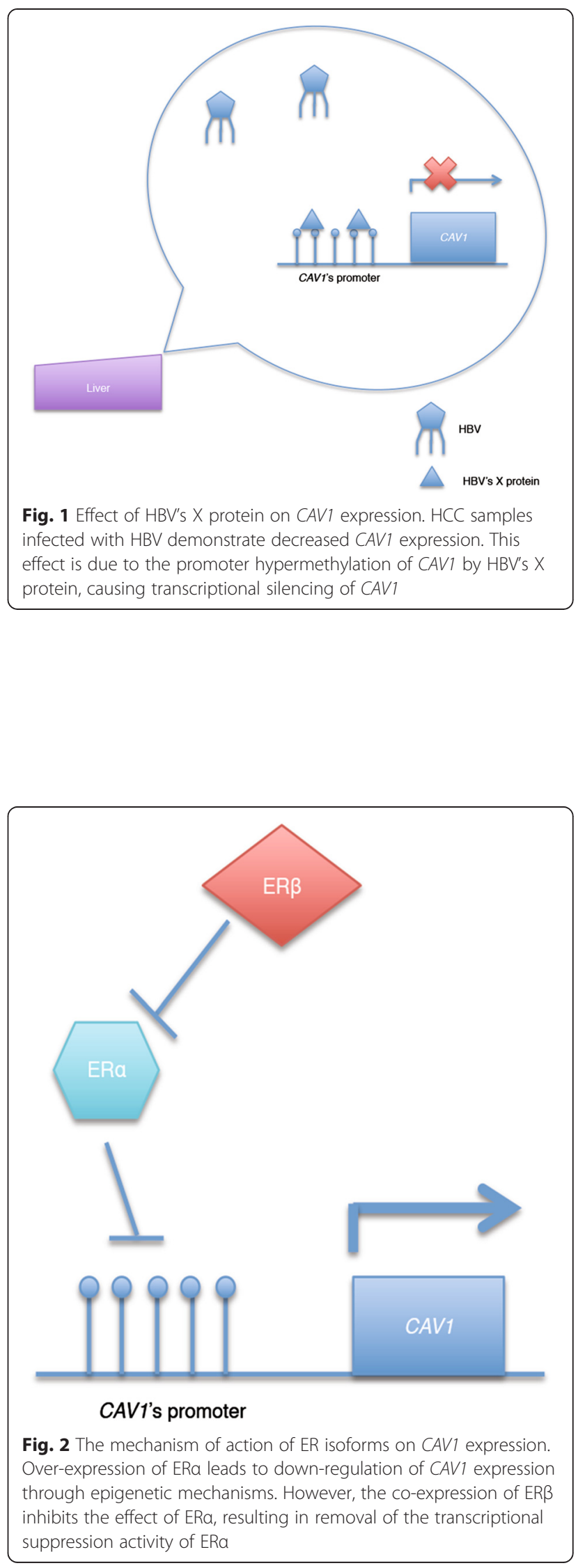
silencing of CAV1 through ectopic expression of ER $\alpha$. In neuronal cells that over-express ER $\alpha, C A V 2$ expression is also down-regulated. 5-AZA treatment results in reexpression of $C A V 2$, but TSA treatment has no effect [80]. This suggests that ER $\alpha$ is able to silence $C A V 2$ through DNA promoter methylation but not histone modification, suggesting another level of regulation.

To date, there are limited data describing the epigenetic regulation of PTRF. PTRF is down-regulated in breast cancer cell lines and tissues and this is related to promoter hypermethylation since PTRF was successfully restored through 5-AZA treatment [43].

\section{Summary of epigenetics and caveolae related genes}

There is growing evidence of a role of epigenetic mechanisms in regulating CAV1, particularly in cancer (Table 1). These effects appear to be cell type specific and different epigenetic mechanisms may be involved in cells from different tissues. There is still limited knowledge on how epigenetics may regulate other caveolae related genes (CAV2, $C A V 3$ and PTRF).

\section{Evidence of microRNA regulation of CAV1, CAV2 and PTRF} MicroRNAs (miRNAs) are able to regulate target transcription and hence protein expression through binding to the 3'-untranslated region of the matching target mRNA [81, 82]. These small nucleotides have been reported to be widely involved in physiological and pathophysiological processes such as apoptosis [83], cellular differentiation [84] and oncogenesis [85].

miRNAs have been shown to act as both tumor promoters and suppressors. Evidence suggests that miRNA133a may act as an upstream regulator of $C A V 1$ expression in head and neck squamous cell carcinoma (HNCC) as the expression of miRNA-133a is down-regulated while CAV1 is up-regulated in HNCC [86]. Luciferase reporter assays showed that miRNA-133a interacts directly with CAV1 mRNA and transfection with a mirRNA-133a mimic results in down-regulated CAV1 expression [86].

In vivo, a diet high in potassium results in increased expression of renal outer medullary potassium (ROMK) channels, an effect thought to be mediated by upregulation of miRNA-802 [87]. The 3'-untranslated region (UTR) of CAV1 contains sequences that allow direct interaction with miRNA-802. CAV1 inhibits ROMK channel activity by interacting with the $\mathrm{N}$-terminus of ROMK channels [87]. When potassium increases, up-regulation of miRNA-802 occurs which down-regulates CAV1's expression by binding to the 3'UTR of CAV1. As CAV1 is able to interact with the N-terminus of the ROMK channels (to down-regulate its expression) down-regulation of CAV1 by miRNA-802 results in up-regulation of the ROMK channels (Fig. 3) [87].
In obese mice, miRNA-103 and 107 are up-regulated and may contribute to impaired glucose homeostasis [88]. Knocking down both miRNAs results in an improved response to insulin and glucose homeostasis [88]. CAV1 regulates insulin signaling [89] and CAV1 is reported to be a target for both miRNA-103 and 107 [88]. Knocking down both miRNAs results in up-regulation of CAV1 [88] and a stabilization of insulin receptors and a responsive insulin signaling mechanism [88]. The findings suggest the potential use of miRNA-103 and 107 as therapeutic targets in treating diabetes and obesity.

CAV1 has been shown to be a direct target for miRNA-199a-5p in the context of tissue fibrosis of several organs (liver, kidney, lungs) [90]. Up-regulation of miRNA-199a-5p in these tissues results in downregulation of CAV1 [90]. Interestingly, TGF- $\beta$, a factor involved in fibrosis, induces the expression of miRNA199a-5p, which in turn causes the down-regulation of CAV1 in these tissues [90]. In porcine adipocytes, there is a high expression of miRNA-199a-5p [91]. Overexpression of miRNA-199a-5p increases proliferation of pre-adipocytes and inhibits the deposition of lipid in adipocytes [91]. CAV1 has been shown to be involved in lipogenesis $[92,17]$ and potentially miRNA-199a-5p may play a role in controlling proliferation of adipocytes, partly through regulating the expression of CAV1.

In porcine kidney epithelial (PK15) cells, miRNA-124 has been shown to directly interact with CAV1. In these cells over-expression of miRNA-124 reduces CAV1 expression at both mRNA and protein levels, thus reducing caveolae density and is associated with reduction in pathogen uptake [93]. Therefore, expression of miRNA124 is proposed to be an important event that inhibits invasion of pathogens in the kidney through downregulation of $C A V 1$, and hence caveolae [93].

Docosahexaenoic acid (DHA) has been reported to modulate the transcriptome of miRNAs in lipid metabolism [94]. Exposure to DHA significantly increases the expression of miRNA-192 in enterocytes and CAV1 is predicted to be a target for miRNA-192. Over-expression of miRNA192, results in reduced CAV1 expression [94]. However, the biological significance of this relationship is not yet known.

Expression of miRNA-199a-3p has been reported to be critical in promoting proliferation and survival of endothelial and breast cancer cells. CAV2 has been shown to be a target of miRNA-199a-3p [95] with overexpression of $C A V 2$ inhibiting the effect exerted by miRNA-199a-3p in promoting proliferation, survival and sensitivity of cancer cells to anticancer drugs [95]. The interaction between miRNA-199a-3p and CAV2 may provide an interesting target for intervention in cancer.

Loss of miRNA-218 and up-regulation of CAV2 have been observed in renal cell carcinoma (RCC) [96]. Over- 


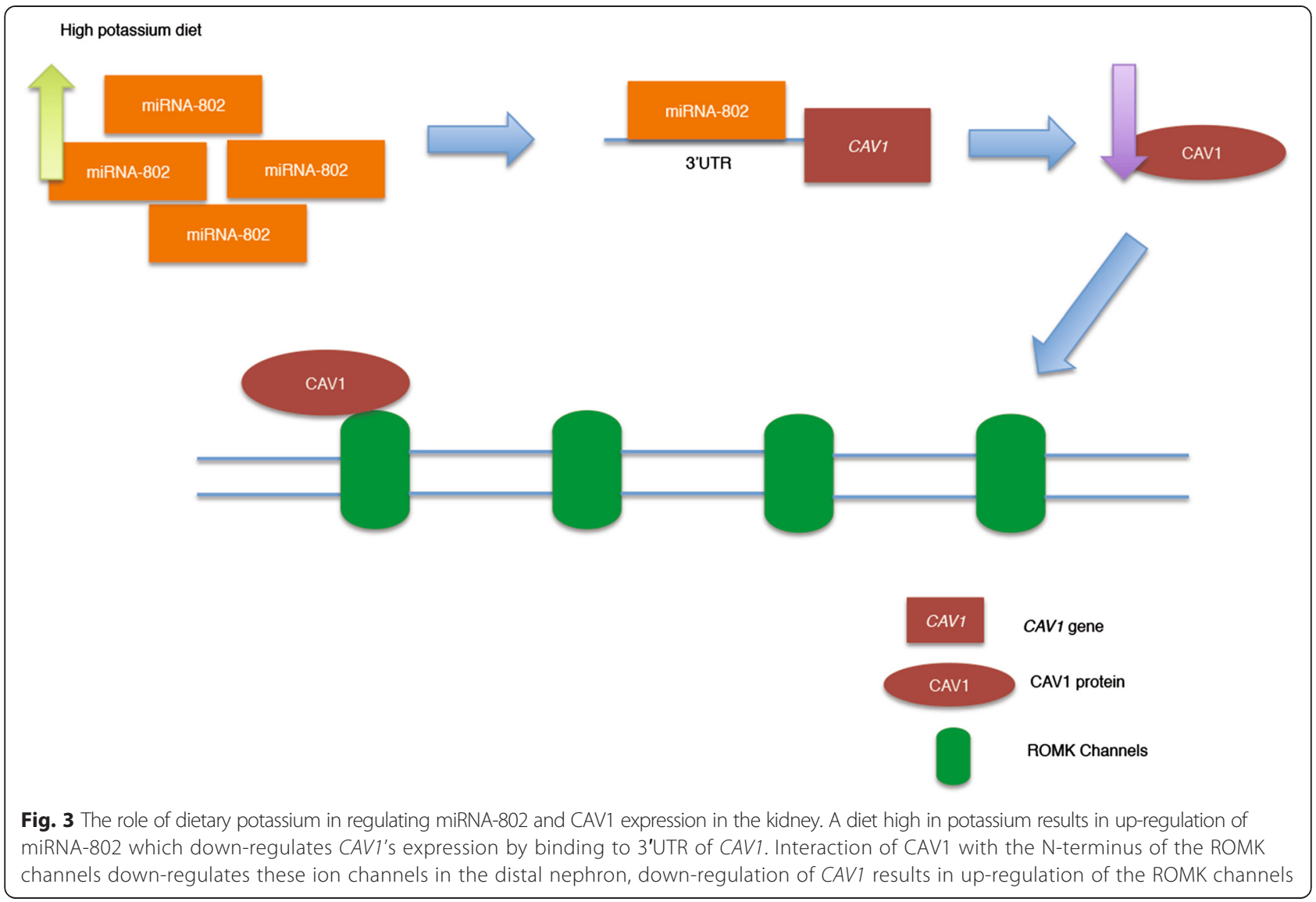

expression of miRNA-218 and knocking down CAV2 significantly inhibits cellular proliferation, migration and invasion of RCC [96]. Gene expression studies reveal $C A V 2$ to be regulated by miRNA-218. It has been suggested that miRNA-218 acts as tumor suppressor by regulating $C A V 2$, possibly through the focal adhesion pathway in RCC [96].

Interestingly, it has been shown that intestinal Salmonella infection is associated with miRNA-29a and CAV2. CAV2 has been shown to be a direct target for miRNA-29a [97]. Infection with Salmonella causes upregulation of miRNA-29a, which in turn results in down-regulation of $C A V 2$ and this is associated with reduced proliferation of intestinal epithelial cells and increased bacterial uptake in the intestinal epithelial cells [97]. Further, over-expression of CAV2 or inhibition of miRNA-29a leads to activation of CDC24 (an important molecule that promotes the uptake of Salmonella into cells), suggesting a possible mechanistic pathway for Salmonella infection [97].

To date, there are no findings that describe a relationship between miRNA and PTRF. However, a recent study suggests that expression of PTRF may modulate the content of miRNA in extracellular vesicles secreted from prostate cancer cells [98].

\section{Summary of miRNA and caveolae related genes}

The discovery and identification of miRNAs is beginning to provide understanding of the upstream regulatory mechanisms that regulate the expression of caveolae related genes. Some evidence is available for a relationship between miRNA and CAV1 and CAV2 (Table 2). However, the lack of the knowledge between miRNA and other caveolae related genes warrants further investigation.

\section{Perspective}

Evidence suggests that environment and lifestyle factors may alter the epigenetic and miRNA profile in humans and contribute to disease [99]. As discussed above, caveolae related genes have been shown to play a role in the pathophysiology of various disease states, especially cancer. Although there is no evidence yet available that environmental changes or diets affect caveolae related genes epigenetically, growing evidence suggests that diet could affect the expression of miRNAs which will then affect the expression of caveolae related genes. Furthermore, it would be interesting to investigate the downstream effects of epigenetic changes to cellular physiology and pathophysiology. Currently, limited evidence is available on this aspect as most of the studies focus on the interaction of 
Table 2 Relationship between miRNA and CAV1 and CAV2 in health and disease

\begin{tabular}{lll}
\hline miRNA & $\begin{array}{l}\text { Target caveolae } \\
\text { related gene }\end{array}$ & Changes observed and involvement in health and diseases \\
\hline miRNA-133a & CAV1 & miRNA-133a is up-regulated in head and neck squamous cell carcinoma and down-regulates \\
CAV1 [86] & miRNA-802 is increased and up-regulates potassium channel expression in kidney by down-regulating \\
miRNA-802 & CAV1 [87] & miRNA-103 is up-regulated in obese animals and associated with impaired glucose homeostasis \\
miRNA-103 & byV1 & miRNA-107 is up-regulated in obese animals and associated with impaired glucose homeostasis \\
miRNA-107 & CAV1 & down-regulating CAV1 [88] \\
miRNA-199a-5p & CAV1 & miRNA-199a-5p is over-expressed in tissue fibrosis and pre-adipocytes, affects tissue fibrosis and \\
proliferation of pre-adipocytes [91, 90] & miRNA-124 down-regulates CAV1 and caveolae to prevent uptake of pathogens in kidney cells [93] \\
miRNA-124 & CAV1 & Exposure to DHA up-regulates miRNA-192 and down-regulates CAV1 [94] \\
miRNA-192 & CAV1 & miRNA-199a-3p is up-regulated in breast cancer and down-regulates CAV2 [95] \\
miRNA-199a-3p & CAV2 & miRNA-128 is down-regulated in renal cell carcinoma and up-regulates CAV2 [96] \\
miRNA-218 & CAV2 & miRNA-29a is up-regulated following Salmonella infection and down-regulates CAV2 [97] \\
miRNA-29a & CAV2 &
\end{tabular}

epigenetic changes to a particular caveolae related gene but not the downstream effects (eg: changes in cellular signaling mechanisms).

The involvement of mutations of the caveolae related genes may also contribute to changes in cellular physiology and pathophysiology. Mutations of CAV1 and PTRF have been shown to be involved in congenital lipodystrophy [100, 101]. As yet there is no evidence available that epigenetic changes in expression of these genes causes lipodystrophic effects, this may suggest that epigenetic changes and mutations of caveolae related genes may predispose to different disease conditions through these two different pathways. Currently there are limited data concerning genetic mutations of $C A V 2$ or other caveolae associated genes.

Potentially, changes in the epigenetic status of caveolae related genes could be developed as a biomarker for diseases, in particular cancers. This could have several advantages. Firstly, DNA is more stable than RNA and secondly there are difficulties in differentiating between RNA from normal and tumor cells, meaning that there are advantages in using DNA as a biomarker over RNA $[102,103]$. Furthermore, DNA promoter hypermethylation occurs uniquely in the $\mathrm{CpG}$ rich area in the promoter whereas genetic mutations can occur randomly within the coding and non-coding region, and promoter hypermethylation is an all-or-none event that can be detected easily with a single pair of primers. Lastly, minimally invasive methods can be used to collect samples (for example urine and plasma) that can then be used to detect epigenetic changes [104, 103]. Potentially, caveolae related genes that are silenced through epigenetic mechanisms may be a useful biomarker for diagnostic purposes in the future.
miRNA has been reported to be dysregulated in a variety of disease conditions. Even though the use of siRNA as a therapeutic target is being clinically trialed, the use of siRNA as a therapeutic target still poses some challenges. The high specificity, low toxicity, unique biogenesis and mechanism of action and the multiple targeting ability of miRNA provide advantages over siRNA. With the recognition of miRNA-caveolae related gene pathways in various disease states, miRNA may potentially be a useful tool for gene intervention. Nevertheless, a single miRNA is predicted to be able to bind to several hundreds of different mRNA [105]. Therefore, should a potential miRNA be developed as a therapeutic target, it would need to be targeted to a specific tissue to avoid unwanted effects which may occur in other tissues in the body. Thus, with the emerging knowledge of the role of miRNA in regulating caveolae related genes, modulating the expression of these key miRNAs could be a useful therapeutic tool, as caveolae related genes have been described to play important roles in health and disease.

\section{Conclusion}

Caveolae related genes have been shown to play important roles in health and disease. Apart from genetic mutations, growing evidence suggests that epigenetic mechanisms may provide an upstream regulatory switch to control the expression of caveolae related genes hence contributing to disease conditions. Potentially, these two events may occur concurrently or exclusively to promote disease progression. Identification of epigenetic modifications may open new doors in biomarker and therapeutic target development to complement the current options that have been developed for genetic mutations. Much of the current evidence is focused on the changes in CAV1 expression by methylation, 
acetylation and miRNA and less is known for $C A V 2$ and $P T R F$. Therefore, further studies are required to investigate whether altering the epigenetic state of these caveolae related genes can affect disease progression and if they can be used as biomarkers for disease identification.

\begin{abstract}
Abbreviations
CAV1: Caveolin-1; CAV2: Caveolin-2; CAV3: Caveolin-3; PTRF: Polymerase-1 and transcript release factor; 5-AZA: 5-AZA-2'-deoxycytidine; TSA: Trichostatin-A; DNA: Deoxyribonucleic acid; RNA: Ribonucleic acid; miRNA: Micro-ribonucleic acid; CpGi: CpG island; HCC: Hepatocellular carcinoma; HNCC: Head and neck squamous cell carcinoma; RCC: Renal cell carcinoma; DHA: Docosahexaenoic acid; TGF- $\beta$ : Transforming growth factor beta; ROMK: Renal outer medullary potassium; ER: Estrogen receptor; HBV: Hepatitis B Virus; IBC: Inflammatory breast cancer; kb: kilo base; mRNA: Messenger ribonucleic acid.
\end{abstract}

\section{Competing interests}

The authors declare that they have no competing interests.

\section{Authors' contributions}

JYL designed and prepared the manuscript and diagrams. HDN provided guidance and editing of the overall manuscript preparation. Both authors read and approved the finalized manuscript.

\section{Authors' information}

$J \mathrm{YL}$ is a PhD Student at the University of Otago

$\mathrm{HDN}$ (BSc Hons, MB ChB, MD) is Professor of Anatomy at the University of Otago.

\section{Acknowledgments}

We would like to thank the University of Otago for the Doctoral Scholarship awarded to JYL. This work is supported by University of Otago.

\section{Received: 4 March 2015 Accepted: 15 June 2015}

Published online: 26 June 2015

\section{References}

1. Yamada $E$. The fine structure of the gall bladder epithelium of the mouse. J Biophys Biochem Cytol. 1955; 1(5):445-58

2. Parton RG, Simons K. The multiple faces of caveolae. Nat Rev Mol Cell Biol. 2007;8(3):185-94

3. Parton RG, del Pozo MA. Caveolae as plasma membrane sensors, protectors and organizers. Nat Rev Mol Cell Biol. 2013;14(2):98-112.

4. Glenney Jr JR. The sequence of human caveolin reveals identity with VIP21, a component of transport vesicles. FEBS Lett. 1992;314(1):45-8.

5. Scherer PE, Okamoto T, Chun M, Nishimoto I, Lodish HF, Lisanti MP. Identification, sequence, and expression of caveolin-2 defines a caveolin gene family. Proc Natl Acad Sci U S A. 1996;93(1):131-5.

6. Tang Z, Scherer PE, Okamoto T, Song K, Chu C, Kohtz DS, et al. Molecular cloning of caveolin-3, a novel member of the caveolin gene family expressed predominantly in muscle. J Biol Chem. 1996;271(4):2255-61.

7. Hill MM, Bastiani M, Luetterforst R, Kirkham M, Kirkham A, Nixon SJ, et al. PTRF-Cavin, a conserved cytoplasmic protein required for caveola formation and function. Cell. 2008;132(1):113-24.

8. Mineo C, Ying YS, Chapline C, Jaken S, Anderson RG. Targeting of protein kinase Calpha to caveolae. J Cell Biol. 1998;141(3):601-10.

9. McMahon KA, Zajicek H, Li WP, Peyton MJ, Minna JD, Hernandez VJ, et al. SRBC/cavin-3 is a caveolin adapter protein that regulates caveolae function. EMBO J. 2009;28(8):1001-15.

10. Bastiani M, Liu L, Hill MM, Jedrychowski MP, Nixon SJ, Lo HP, et al. MURC/ Cavin-4 and cavin family members form tissue-specific caveolar complexes. J Cell Biol. 2009;185(7):1259-73.

11. Glenney Jr JR, Zokas L. Novel tyrosine kinase substrates from Rous sarcoma virus-transformed cells are present in the membrane skeleton. J Cell Biol. 1989:108(6):2401-8.

12. Rothberg KG, Heuser JE, Donzell WC, Ying YS, Glenney JR, Anderson RG. Caveolin, a protein component of caveolae membrane coats. Cell. 1992;68(4):673-82.

13. Le Lay S, Kurzchalia TV. Getting rid of caveolins: phenotypes of caveolin-deficient animals. Biochim Biophys Acta. 2005;1746(3):322-33.
14. Drab M, Verkade P, Elger M, Kasper M, Lohn M, Lauterbach B, et al. Loss of caveolae, vascular dysfunction, and pulmonary defects in caveolin-1 gene-disrupted mice. Science. 2001;293(5539):2449-52.

15. Fra AM, Williamson E, Simons K, Parton RG. De novo formation of caveolae in lymphocytes by expression of VIP21-caveolin. Proc Natl Acad Sci U S A. 1995;92(19):8655-9.

16. Cao G, Yang G, Timme TL, Saika T, Truong LD, Satoh T, et al. Disruption of the caveolin-1 gene impairs renal calcium reabsorption and leads to hypercalciuria and urolithiasis. Am J Pathol. 2003;162(4):1241-8.

17. Cohen AW, Razani B, Wang XB, Combs TP, Williams TM, Scherer PE, et al. Caveolin-1-deficient mice show insulin resistance and defective insulin receptor protein expression in adipose tissue. Am J Physiol Cell Physiol. 2003;285(1):C222-35.

18. Hassan GS, Jasmin JF, Schubert W, Frank PG, Lisanti MP. Caveolin-1 deficiency stimulates neointima formation during vascular injury. Biochemistry. 2004;43(26):8312-21.

19. Cohen AW, Hnasko R, Schubert W, Lisanti MP. Role of caveolae and caveolins in health and disease. Physiol Rev. 2004;84(4):1341-79.

20. Li S, Galbiati F, Volonte D, Sargiacomo M, Engelman JA, Das K, et al. Mutational analysis of caveolin-induced vesicle formation. Expression of caveolin-1 recruits caveolin-2 to caveolae membranes. FEBS Lett. 1998;434(1-2):127-34.

21. Razani B, Wang XB, Engelman JA, Battista M, Lagaud G, Zhang XL, et al. Caveolin-2-deficient mice show evidence of severe pulmonary dysfunction without disruption of caveolae. Mol Cell Biol. 2002;22(7):2329-44.

22. Das K, Lewis RY, Scherer PE, Lisanti MP. The membrane-spanning domains of caveolins- 1 and -2 mediate the formation of caveolin hetero-oligomers. Implications for the assembly of caveolae membranes in vivo. J Biol Chem. 1999;274(26):18721-8.

23. Rybin VO, Grabham PW, Elouardighi H, Steinberg SF. Caveolae-associated proteins in cardiomyocytes: caveolin-2 expression and interactions with caveolin-3. Am J Physiol Heart Circ Physiol. 2003;285(1):H325-32.

24. Song KS, Scherer PE, Tang Z, Okamoto T, Li S, Chafel M, et al. Expression of caveolin-3 in skeletal, cardiac, and smooth muscle cells. Caveolin-3 is a component of the sarcolemma and co-fractionates with dystrophin and dystrophin-associated glycoproteins. J Biol Chem. 1996;271(25):15160-5.

25. Capozza F, Cohen AW, Cheung MW, Sotgia F, Schubert W, Battista M, et al. Muscle-specific interaction of caveolin isoforms: differential complex formation between caveolins in fibroblastic vs. muscle cells. Am J Physiol Cell Physiol. 2005;288(3):C677-91.

26. Capozza F, Combs TP, Cohen AW, Cho YR, Park SY, Schubert W, et al. Caveolin-3 knockout mice show increased adiposity and whole body insulin resistance, with ligand-induced insulin receptor instability in skeletal muscle. Am J Physiol Cell Physiol. 2005;288(6):C1317-31.

27. Galbiati F, Engelman JA, Volonte D, Zhang XL, Minetti C, Li M, et al. Caveolin-3 null mice show a loss of caveolae, changes in the microdomain distribution of the dystrophin-glycoprotein complex, and t-tubule abnormalities. J Biol Chem. 2001;276(24):21425-33.

28. Park DS, Woodman SE, Schubert W, Cohen AW, Frank PG, Chandra M, et al. Caveolin-1/3 double-knockout mice are viable, but lack both muscle and non-muscle caveolae, and develop a severe cardiomyopathic phenotype. Am J Pathol. 2002;160(6):2207-17.

29. Jansa P, Mason SW, Hoffmann-Rohrer U, Grummt I. Cloning and functional characterization of PTRF, a novel protein which induces dissociation of paused ternary transcription complexes. EMBO J. 1998;17(10):2855-64.

30. Jansa P, Grummt I. Mechanism of transcription termination: PTRF interacts with the largest subunit of RNA polymerase I and dissociates paused transcription complexes from yeast and mouse. Mol Gen Genet. 1999;262(3):508-14.

31. Wanaski SP, Ng BK, Glaser M. Caveolin scaffolding region and the membrane binding region of SRC form lateral membrane domains. Biochemistry. 2003;42(1):42-56.

32. Rajab A, Straub V, McCann L, Seelow D, Varon R, Barresi R, et al. Fatal cardiac arrhythmia and long-QT syndrome in a new form of congenital generalized lipodystrophy with muscle rippling (CGL4) due to PTRF-CAVIN mutations. PLoS Genet. 2010;6(3):e1000874.

33. Gould ML, Williams G, Nicholson HD. Changes in caveolae, caveolin, and polymerase 1 and transcript release factor (PTRF) expression in prostate cancer progression. Prostate. 2010;70(15):1609-21.

34. Liu L, Brown D, McKee M, Lebrasseur NK, Yang D, Albrecht KH, et al. Deletion of Cavin/PTRF causes global loss of caveolae, dyslipidemia, and glucose intolerance. Cell Metab. 2008;8(4):310-7. 
35. Liu L, Pilch PF. A critical role of cavin (polymerase I and transcript release factor) in caveolae formation and organization. J Biol Chem. 2008;283(7):4314-22.

36. Govender P, Romero F, Shah D, Paez J, Ding SY, Liu L, et al. Cavin1; a regulator of lung function and macrophage phenotype. PLoS One. 2013;8(4):e62045.

37. Sward K, Sadegh MK, Mori M, Erjefalt JS, Rippe C. Elevated pulmonary arterial pressure and altered expression of Ddah1 and Arg1 in mice lacking cavin-1/PTRF. Physiol Rep. 2013;1(1):e00008.

38. Sward K, Albinsson S, Rippe C. Arterial dysfunction but maintained systemic blood pressure in cavin-1-deficient mice. PLoS One. 2014;9(3):e92428.

39. Low JY, Nicholson HD. Emerging role of polymerase-1 and transcript release factor (PTRF/ Cavin-1) in health and disease. Cell Tissue Res. 2014;357(3):505-13.

40. Hansen CG, Bright NA, Howard G, Nichols BJ. SDPR induces membrane curvature and functions in the formation of caveolae. Nat Cell Biol. 2009;11(7):807-14.

41. Briand N, Dugail I, Le Lay S. Cavin proteins: New players in the caveolae field. Biochimie. 2011;93(1):71-7.

42. Tagawa M, Ueyama T, Ogata T, Takehara N, Nakajima N, Isodono K, et al. MURC, a muscle-restricted coiled-coil protein, is involved in the regulation of skeletal myogenesis. Am J Physiol Cell Physiol. 2008;295(2):C490-8.

43. Bai L, Deng X, Li Q, Wang M, An W, Deli A, et al. Down-regulation of the cavin family proteins in breast cancer. J Cell Biochem. 2012;113(1):322-8.

44. Michel V, Bakovic M. Lipid rafts in health and disease. Biol Cell. 2007:99(3):129-40.

45. Verma M, Srivastava S. Epigenetics in cancer: implications for early detection and prevention. Lancet Oncol. 2002;3(12):755-63

46. De Carvalho DD, You JS, Jones PA. DNA methylation and cellular reprogramming. Trends Cell Biol. 2010;20(10):609-17.

47. Gowher $\mathrm{H}$, Jeltsch A. Mechanism of inhibition of DNA methyltransferases by cytidine analogs in cancer therapy. Cancer Biol Ther. 2004;3(11):1062-8

48. Stresemann C, Lyko F. Modes of action of the DNA methyltransferase inhibitors azacytidine and decitabine. Int J Cancer. 2008;123(1):8-13.

49. Bui C, Ouzzine M, Talhaoui I, Sharp S, Prydz K, Coughtrie MW, et al. Epigenetics: methylation-associated repression of heparan sulfate 3-O-sulfotransferase gene expression contributes to the invasive phenotype of H-EMC-SS chondrosarcoma cells. FASEB J. 2010;24(2):436-50.

50. Irizarry RA, Ladd-Acosta C, Wen B, Wu Z, Montano C, Onyango P, et al. The human colon cancer methylome shows similar hypo- and hypermethylation at conserved tissue-specific CpG island shores. Nat Genet. 2009;41(2):178-86.

51. Doi A, Park $I H$, Wen B, Murakami P, Aryee MJ, Irizarry R, et al. Differential methylation of tissue- and cancer-specific $\mathrm{CpG}$ island shores distinguishes human induced pluripotent stem cells, embryonic stem cells and fibroblasts. Nat Genet. 2009:41(12):1350-3.

52. Allfrey VG, Faulkner R, Mirsky AE. Acetylation and methylation of histones and their possible role in the regulation of RNA synthesis. Proc Natl Acad Sci U S A. 1964:51:786-94.

53. $\mathrm{Ng} \mathrm{HH}$, Bird A. Histone deacetylases: silencers for hire. Trends Biochem Sci. 2000;25(3):121-6.

54. Yoshida M, Horinouchi S, Beppu T. Trichostatin A and trapoxin: novel chemical probes for the role of histone acetylation in chromatin structure and function. Bioessays. 1995;17(5):423-30

55. Engelman JA, Zhang XL, Lisanti MP. Sequence and detailed organization of the human caveolin-1 and -2 genes located near the D7S522 locus (7q31.1). Methylation of a CpG island in the 5' promoter region of the caveolin-1 gene in human breast cancer cell lines. FEBS Lett. 1999;448(2-3):221-30.

56. Syeed N, Hussain F, Husain SA, Siddiqi MA. 5'-CpG island promoter hypermethylation of the CAV-1 gene in breast cancer patients of Kashmir. Asian Pac J Cancer Prev. 2012;13(1):371-5.

57. Chen ST, Lin SY, Yeh KT, Kuo SJ, Chan WL, Chu YP, et al. Mutational, epigenetic and expressional analyses of caveolin-1 gene in breast cancers. Int J Mol Med. 2004;14(4):577-82.

58. Alevizos L, Kataki A, Derventzi A, Gomatos I, Loutraris C, Gloustianou G, et al. Breast cancer nodal metastasis correlates with tumour and lymph node methylation profiles of Caveolin-1 and CXCR4. Clin Exp Metastasis. 2014;31(5):511-20.

59. Deb M, Sengupta D, Kar S, Rath SK, Parbin S, Shilpi A, et al. Elucidation of caveolin 1 both as a tumor suppressor and metastasis promoter in light of epigenetic modulators. Tumour Biol. 2014;35(12):12031-47.

60. Van den Eynden GG, Van Laere SJ, Van der Auwera I, Merajver SD, Van Marck EA, van Dam P, et al. Overexpression of caveolin-1 and -2 in cell lines and in human samples of inflammatory breast cancer. Breast Cancer Res Treat. 2006;95(3):219-28.
61. Rao X, Evans J, Chae H, Pilrose J, Kim S, Yan P, et al. CpG island shore methylation regulates caveolin-1 expression in breast cancer. Oncogene. 2013;32(38):4519-28.

62. Cui J, Rohr LR, Swanson G, Speights VO, Maxwell T, Brothman AR. Hypermethylation of the caveolin-1 gene promoter in prostate cancer Prostate. 2001;46(3):249-56.

63. Yang B, Bhusari S, Kueck J, Weeratunga P, Wagner J, Leverson G, et al. Methylation profiling defines an extensive field defect in histologically normal prostate tissues associated with prostate cancer. Neoplasia. 2013;15(4):399-408.

64. Bachmann N, Haeusler J, Luedeke M, Kuefer R, Perner S, Assum G, et al. Expression changes of CAV1 and EZH2, located on 7q31 approximately q36, are rarely related to genomic alterations in primary prostate carcinoma. Cancer Genet Cytogenet. 2008;182(2):103-10.

65. Goetz JG, Lajoie P, Wiseman SM, Nabi IR. Caveolin-1 in tumor progression: the good, the bad and the ugly. Cancer Metastasis Rev. 2008;27(4):715-35.

66. Dennis JW, Pawling J, Cheung P, Partridge E, Demetriou M. UDP-N-acetylglucosamine:alpha-6-D-mannoside beta1,6 N-acetylglucosaminyltransferase $\mathrm{V}$ (Mgat5) deficient mice. Biochim Biophys Acta. 2002;1573(3):414-22.

67. Takenaka Y, Fukumori T, Raz A. Galectin-3 and metastasis. Glycoconj J. 2004;19(7-9):543-9.

68. Kunze E, Von Bonin F, Werner C, Wendt M, Schlott T. Transitional cell carcinomas and nonurothelial carcinomas of the urinary bladder differ in the promoter methylation status of the caveolin-1, hDAB2IP and p53 genes, but not in the global methylation of Alu elements. Int J Mol Med. 2006;17(1):3-13.

69. Kunze E, Schlott T. High frequency of promoter methylation of the 14-3-3 sigma and CAGE-1 genes, but lack of hypermethylation of the caveolin-1 gene, in primary adenocarcinomas and signet ring cell carcinomas of the urinary bladder. Int J Mol Med. 2007;20(4):557-63.

70. Sunaga N, Miyajima K, Suzuki M, Sato M, White MA, Ramirez RD, et al. Different roles for caveolin-1 in the development of non-small cell lung cancer versus small cell lung cancer. Cancer Res. 2004;64(12):4277-85.

71. Wiechen K, Diatchenko L, Agoulnik A, Scharff KM, Schober H, Arlt K, et al. Caveolin-1 is down-regulated in human ovarian carcinoma and acts as a candidate tumor suppressor gene. Am J Pathol. 2001;159(5):1635-43.

72. Lin SY, Yeh KT, Chen WT, Chen HC, Chen ST, Chang JG. Promoter CpG methylation of caveolin-1 in sporadic colorectal cancer. Anticancer Res. 2004;24(3a):1645-50.

73. Mori Y, Cai K, Cheng Y, Wang S, Paun B, Hamilton JP, et al. A genome-wide search identifies epigenetic silencing of somatostatin, tachykinin-1, and 5 other genes in colon cancer. Gastroenterology. 2006;131(3):797-808.

74. Ha TK, Her NG, Lee MG, Ryu BK, Lee JH, Han J, et al. Caveolin-1 increases aerobic glycolysis in colorectal cancers by stimulating HMGA1-mediated GLUT3 transcription. Cancer Res. 2012;72(16):4097-109.

75. Hirasawa Y, Arai M, Imazeki F, Tada M, Mikata R, Fukai K, et al. Methylation status of genes upregulated by demethylating agent 5-aza-2'-deoxycytidine in hepatocellular carcinoma. Oncology. 2006;71(1-2):77-85.

76. Dewantoro O, Gani RA, Akbar N. Hepatocarcinogenesis in viral Hepatitis B infection: the role of HBx and p53. Acta Med Indones. 2006;38(3):154-9.

77. Yan J, Lu Q, Dong J, Li X, Ma K, Cai L. Hepatitis B virus X protein suppresses caveolin-1 expression in hepatocellular carcinoma by regulating DNA methylation. BMC Cancer. 2012;12:353.

78. McEwen BS. Invited review: Estrogens effects on the brain: multiple sites and molecular mechanisms. J Appl Physiol (1985). 2001;91(6):2785-801.

79. Behl C. Oestrogen as a neuroprotective hormone. Nat Rev Neurosci. 2002;3(6):433-42

80. Zschocke J, Manthey D, Bayatti N, van der Burg B, Goodenough S, Behl C. Estrogen receptor alpha-mediated silencing of caveolin gene expression in neuronal cells. J Biol Chem. 2002;277(41):38772-80.

81. Krek A, Grun D, Poy MN, Wolf R, Rosenberg L, Epstein EJ, et al. Combinatorial microRNA target predictions. Nat Genet. 2005;37(5):495-500

82. Farazi TA, Juranek SA, Tuschl T. The growing catalog of small RNAs and their association with distinct Argonaute/Piwi family members. Development. 2008;135(7):1201-14.

83. Bostjancic E, Jerse M, Glavac D, Zidar N. miR-1, miR-133a/b, and miR-208a in human fetal hearts correlate to the apoptotic and proliferation markers. Exp Biol Med (Maywood). 2014;240(2):211-9.

84. Chen JF, Mandel EM, Thomson JM, Wu Q, Callis TE, Hammond SM, et al. The role of microRNA-1 and microRNA-133 in skeletal muscle proliferation and differentiation. Nat Genet. 2006;38(2):228-33.

85. Iorio MV, Ferracin M, Liu CG, Veronese A, Spizzo R, Sabbioni S, et al. MicroRNA gene expression deregulation in human breast cancer. Cancer Res. 2005;65(16):7065-70 
86. Nohata N, Hanazawa T, Kikkawa N, Mutallip M, Fujimura L, Yoshino H, et al. Caveolin-1 mediates tumor cell migration and invasion and its regulation by miR-133a in head and neck squamous cell carcinoma. Int J Oncol. 2011;38(1):209-17.

87. Lin DH, Yue P, Pan C, Sun P, Wang WH. MicroRNA 802 stimulates ROMK channels by suppressing caveolin-1. J Am Soc Nephrol. 2011;22(6):1087-98.

88. Trajkovski M, Hausser J, Soutschek J, Bhat B, Akin A, Zavolan M, et al. MicroRNAs 103 and 107 regulate insulin sensitivity. Nature. 2011;474(7353):649-53

89. Nystrom FH, Chen H, Cong LN, Li Y, Quon MJ. Caveolin-1 interacts with the insulin receptor and can differentially modulate insulin signaling in transfected Cos-7 cells and rat adipose cells. Mol Endocrinol. 1999;13(12):2013-24.

90. Lino Cardenas CL, Henaoui IS, Courcot E, Roderburg C, Cauffiez C, Aubert S, et al. miR-199a-5p Is upregulated during fibrogenic response to tissue injury and mediates TGFbeta-induced lung fibroblast activation by targeting caveolin-1. PLoS Genet. 2013;9(2):e1003291.

91. Shi XE, Li YF, Jia L, Ji HL, Song ZY, Cheng J, et al. MicroRNA-199a-5p affects porcine preadipocyte proliferation and differentiation. Int J Mol Sci. 2014;15(5):8526-38.

92. Razani B, Combs TP, Wang XB, Frank PG, Park DS, Russell RG, et al. Caveolin-1deficient mice are lean, resistant to diet-induced obesity, and show hypertriglyceridemia with adipocyte abnormalities. J Biol Chem. 2002;277(10):8635-47

93. Yang S, Liu X, Li X, Sun S, Sun F, Fan B, et al. MicroRNA-124 reduces caveolar density by targeting caveolin-1 in porcine kidney epithelial PK15 cells. Mol Cell Biochem. 2013;384(1-2):213-9.

94. Gil-Zamorano J, Martin R, Daimiel L, Richardson K, Giordano E, Nicod N, et al. Docosahexaenoic acid modulates the enterocyte Caco-2 cell expression of microRNAs involved in lipid metabolism. J Nutr. 2014;144(5):575-85.

95. Shatseva T, Lee DY, Deng Z, Yang BB. MicroRNA miR-199a-3p regulates cell proliferation and survival by targeting caveolin-2. J Cell Sci. 2011;124(Pt 16):2826-36

96. Yamasaki T, Seki N, Yoshino $H$, Itesako T, Hidaka $H$, Yamada $Y$, et al. MicroRNA-218 inhibits cell migration and invasion in renal cell carcinoma through targeting caveolin-2 involved in focal adhesion pathway. J Urol. 2013;190(3):1059-68.

97. Hoeke L, Sharbati J, Pawar K, Keller A, Einspanier R, Sharbati S. Intestinal Salmonella typhimurium infection leads to miR-29a induced caveolin 2 regulation. PLoS One. 2013;8(6):e67300.

98. Inder KL, Ruelcke JE, Petelin L, Moon H, Choi E, Rae J, et al. Cavin-1/PTRF alters prostate cancer cell-derived extracellular vesicle content and internalization to attenuate extracellular vesicle-mediated osteoclastogenesis and osteoblast proliferation. J Extracell Vesicles. 2014;3

99. Pogribny IP. Epigenetic events in tumorigenesis: putting the pieces together. Exp Oncol. 2010;32(3):132-6

100. Hayashi YK, Matsuda C, Ogawa M, Goto K, Tominaga K, Mitsuhashi S, et al. Human PTRF mutations cause secondary deficiency of caveolins resulting in muscular dystrophy with generalized lipodystrophy. J Clin Invest. 2009;119(9):2623-33.

101. Kim CA, Delepine M, Boutet E, El Mourabit H, Le Lay S, Meier M, et al. Association of a homozygous nonsense caveolin-1 mutation with Berardinelli-Seip congenital lipodystrophy. J Clin Endocrinol Metab. 2008;93(4):1129-34.

102. Issa JP. CpG island methylator phenotype in cancer. Nat Rev Cancer 2004:4(12):988-93.

103. Tost J. DNA methylation: an introduction to the biology and the disease-associated changes of a promising biomarker. Mol Biotechnol. 2010;44(1):71-81.

104. Miyamoto K, Ushijima T. Diagnostic and therapeutic applications of epigenetics. Jpn J Clin Oncol. 2005;35(6):293-301.

105. Nilsen TW. Mechanisms of microRNA-mediated gene regulation in animal cells. Trends Genet. 2007;23(5):243-9.

\section{Submit your next manuscript to BioMed Central and take full advantage of:}

- Convenient online submission

- Thorough peer review

- No space constraints or color figure charges

- Immediate publication on acceptance

- Inclusion in PubMed, CAS, Scopus and Google Scholar

- Research which is freely available for redistribution

Submit your manuscript at www.biomedcentral.com/submit 